\title{
Keanekaragaman Kumbang Antena Panjang (Coleoptera: Cerambycidae) pada Beberapa Perkebunan di Polokarto, Jawa Tengah
}

\author{
Diversity of longhorn beetles (Coleoptera: Cerambycidae) on several \\ plantations in Polokarto, Central Java
}

\author{
Mihwan Sataral ${ }^{1 *}$, Fahri ${ }^{2}$, Tri Atomowidi ${ }^{3}$
${ }^{1}$ Program Studi Agroteknologi, Fakultas Pertanian, Universitas Tompotika, Luwuk 94715, Sulawesi Tengah. ${ }^{2}$ Jurusan Biologi, Fakultas Matematika dan Ilmu Pengetahuan Alam, Universitas Tadulako, Kampus Bumi Tadulako Tondo Palu, Sulawesi Tengah 94118.
${ }^{3}$ Departemen Biologi, Fakultas Matematika dan Ilmu Pengetahuan Alam, Institut Pertanian Bogor, Kampus \\ Darmaga, Bogor 16680.
}

\begin{abstract}
Longhorn beetles are important insect in ecosystem due to their dependence on food sources in various species of plants. This study is to determine the diversity of longhorn beetles in different types of plantations in Polokarto, Central Java. Longhorn beetles were collected using branches of jackfruit (Artocarpus trap). There were 409 longhorn beetles collected, and its belonging to 4 tribes, 5 genera and 10 species. The highest abundance i.e. Sybra alternans (163 individuals) and Pterolophia melanura (96 individuals). The highest diversity of longhorn beetles was found in mixed plantation $(\mathrm{H}=1.846)$, followed by sugarcane plantation $(\mathrm{H}=1.723)$ and teak plantation $(\mathrm{H}=1.51)$. Similarity of longhorn beetles based Bray-Curtis similarity index was highest between mixed plantation and teak plantation (0.795).
\end{abstract}

\section{Keywords: Diversity, longhorn beetles, Central Java}

\begin{abstract}
ABSTRAK
Kumbang antena panjang merupakan serangga penting dalam ekosistem karena ketergantungannya pada sumber makanan di berbagai spesies tanaman. Penelitian ini bertujuan untuk mengetahui keanekaragaman kumbang antena panjang pada berbagai perkebunan di Polokarto, Jawa Tengah. Pengambilan sampel dilakukan dengan menggunakan perangkap cabang tumbuhan nangka (Artocarpus trap). Sebanyak 409 individu terkoleksi, terdiri dari 4 tribe, 5 genus dan 10 spesies. Spesies yang paling melimpah disetiap habitat adalah Sybra alternans (163 individu), kemudian diikuti oleh Pterolophia melanura (96 individu). Keanekaragaman tertinggi pada habitat kebun campuran $(\mathrm{H}=1,846)$ kemudian diikuti pada kebun tebu $(\mathrm{H}=1,723)$ dan paling rendah pada kebun jati $(\mathrm{H}=1,51)$. Kesamaan
\end{abstract}

Coresponding Author: mihwansataral87@gmail.com (phone: +6285240819189) 
komunitas berdasarkan indeks kesamaan Bray-Curtis, tertinggi antara habitat kebun campuran - kebun jati $(0,795)$.

\section{Kata Kunci : Keanekaragaman, kumbang antena panjang, Jawa Tengah}

\section{LATAR BELAKANG}

Konversi ekosistem alami dalam skala global termasuk sistem penggunaan lahan merupakan salah satu penyebab hilangnya keanekaragaman hayati dan merupakan ancaman terhadap fungsi ekosistem dan penggunaan lahan secara berkelanjutan (Hoekstra et al., 2005; Sahabuddin, 2011). Jones et al. (2003) melaporkan bahwa penurunan keragaman rayap terkait dengan deforestasi dan intensifikasi pertanian di Jambi. Susilo et al. (2009) melaporkan terjadi penurunan keanekaragaman kumbang akibat sistem penggunaan lahan dari hutan menjadi perkebunan karet dan sawit. Selain itu, kegiatan manusia seperti penggunaan insektisida di lahan pertanian juga mempengaruhi keanekaragaman dan kelimpahan arthropoda predator yang aktif di permukaan tanah (Herlinda et al., 2008).

Kumbang merupakan sebagian besar dari kelomok serangga yang memainkan peran penting dalam rantai trofik (Dagobert et al., 2008). Kumbang antena panjang (Coleoptera: Cerambycidae) memainkan peran penting dalam proses dekomposisi dan siklus hara dalam ekosistem alami, melalui interaksi dengan kelompok organisme dan sangat penting untuk keseimbangan ekosistem (Nieto \& Alexander, 2010). Kumbang antena panjang berkembang di pohonpohon yang sehat, namun terdapat beberapa spesies berkembang pada pohon yang mulai melapuk (Hanks 1999; Raje et al., 2012). Kumbang dewasa yang bersifat hama bertelur di bawah kulit kayu dan larva, hingga akhirnya larva tersebut membuat lubang besar melalui lapisan kayu sampai ke bagian dalam, hal ini sangat mempengaruhi kualitas kayu bahkan dapat menyebabkan kematian pohon, namun demikian banyak spesies kumbang yang bermanfaat bagi ekosistem hutan (Raje et al., 2012). Kumpulan spesies kumbang antena panjang dapat bervariasi antara hutan yang berbeda jenis (Maeto et al., 2002; Ohsawa, 2004), Selain itu, kelimpahan kumbang antena panjang juga dipengaruhi oleh hutan monokultur (Alekseev, 2007), hal ini terkait dengan banyak jenis tanaman yang tersedia sebagai inang yang digunakan oleh larva kumbang antena panjang ntuk berkembang (Meng et al., 2013). Hutan memiliki kepadatan kumbang yang relatif lebih tinggi dibandingkan dengan daerah perkebunan 
(Goldsmith et al., 2007; Goldsmith, 2007), oleh karena itu kehadiran kumbang antena panjang dapat digunakan sebagai salah satu indikator dari suatu kawasan hutan (Ohsawa, 2010; Noerdjito, 2011).

Wilayah desa Polokarto (kabupaten Sukoharjo) merupakan lahan perkebunan karet milik negara, namun terdapat juga perkebunan dengan skala kecil yang dikelola oleh masyarakat seperti kebun jati, kebun tebu dan juga kebun campuran lainnya. Adanya perbedaan sistem penggunaan lahan di daerah tersebut juga mempengaruhi komunitas serangga termasuk kumbang antena panjang. Dengan dasar itulah maka penelitian ini dilakukan dengan tujuan untuk mengetahui keanekaragaman kumbang antena panjang pada berbagai perkebunan di Polokarto, Jawa Tengah. Informasi yang diperoleh diharapkan memberikan pengetahuan mengenai pengaruh sistem penggunaan lahan seperti kebun jati, kebun tebu dan campuran, terhadap struktur komunitas kumbang antena panjang.

\section{BAHAN DAN METODE}

Lokasi Penelitian. Penelitian dilakukan di lahan perkebunan masyarakat yang terletak di desa Polokarto, kabupaten Sukoharjo, provinsi Jawa Tengah. Penentuan lokasi penelitian berdasarkan perbedaan penggunaan lahan yang dikelola oleh masyarakat setempat yakni kebun jati, kebun tebu dan kebun campuran. Deskripsi masing-masing lokasi penelitian sebagai berikut:

a. Kebun jati; merupakan tanaman monokultur dengan luas $\pm 2 \mathrm{Ha}$, berada pada ketinggian tempat 186 mdpl dan terletak di koordinat geografis 07³8'52.3” - 07³8'54.3” lintang selatan dan $110^{\circ} 55^{\prime} 23.3^{\prime \prime}$ - $110^{\circ} 55^{\prime} 24.3$ "' bujur timur. Umur tanaman sekitar $3-5$ tahun, penutupan tajuk yang kurang, jarang terdapat semak belukar dan banyak terdapat serasah ranting dan daun yang gugur.

b. Kebun tebu; merupakan tanaman musiman dengan luas $\pm 5 \mathrm{Ha}$, berada pada ketinggian $186 \mathrm{mdpl}$ dan terletak di koordinat geografis $07^{\circ} 38^{\prime} 40.9^{\prime \prime}$ lintang selatan dan $110^{\circ} 55^{\prime} 26.7^{\prime \prime}$ bujur timur. Umur tanaman \pm 8 bulan, yang ditanami tumbuhan Gliciridia sp. sebagai pembatas pada tiap-tiap bloknya.

c. Kebun campuran; merupakan tanaman polikultur musiman di sekitar pemukiman, tanpa ada perawatan yang intensif, sehingga banyak terdapat semak belukar.

\section{Pengumpulan Spesimen Kumbang.}

Kumbang antena panjang dikumpulkan dengan menggunakan perangkap tumbuhan nangka atau Artocarpus trap (Nerdjito, 2008), berupa cabang berdaun segar dan 
diikatkan di pohon ketinggian $1 \mathrm{~m}-1,5 \mathrm{~m}$ dari permukaan tanah. Sebanyak 10 perangkap dipasang di masing-masing habitat. Koleksi sampel dilakukan pada hari ke 4, 8, 12 dan 16 setelah perangkap dipasangkan. Koleksi dilakukan dengan cara memukul (beating) bagian cabang, dengan penadah kain putih di bawahnya (Noerdjito, 2009). Kumbang yang dikoleksi kemudian dimasukan ke dalam botol pembunuh yang di dalamnya terdapat kapas yang ditetesi cairan ethyl acetat, setelah itu disimpan ke dalam kertas papilot untuk koleksi kering.

\section{Preservasi dan Identifikasi Spesimen Kumbang.}

Proses pinning dilakukan khusus untuk kumbang yang ukuran tubuhnya lebih dari $10 \mathrm{~mm}$ dengan cara menusukan jarum serangga ke bagian elytra sebelah kanan, sedangkan kumbang yang berukuran kurang dari $10 \mathrm{~mm}$ ditempelkan pada kertas tebal berbentuk segitiga memanjang (panjang $10 \mathrm{~mm}$, lebar $4 \mathrm{~mm}$ ). Proses lebelling dilakukan dengan mencantumkan data lokasi, waktu koleksi dan nama kolektor. Spesimen kumbang kemudian dimasukan ke dalam oven selama 1 minggu dan freezer selama 1 minggu. Proses identifikasi dilakukan di Laboratorium Entomologi, LIPI Cibinong dengan merujuk pada Cherepanov, (1990),
Makihara et al. (2002), Makihara and Noedjito (2004), Heffern (2013) dan Bezark (2014).

Analisis Data. Kumbang yang ditemukan dihitung jumlah individu dan spesiesnya. Data kumbang dianalisis, dengan indeks keanekaragaman Shannon-Wiener $\left(H^{\prime}\right)$ menggunakan program $\mathrm{R}$ versi 3.1 .3 (https://www.r-project.org) dan indeks kesamaan Bray-Curtis menggunakan program PAST versi $2.17 \mathrm{c}$ (http://folk.uio.no/ohammer/past) (Sataral et al., 2015). Kurva akumulasi spesies dikontruksi berdasarkan jumlah individu yang didapatkan pada masing-masing waktu koleksi menggunakan program EstimateS versi 9 dengan tingkat kepercayaan 95\% (Sataral, 2015).

\section{HASIL DAN PEMBAHASAN}

Kumbang antena panjang yang didapatkan dalam penelitian ini terdiri dari 4 tribe, 5 genus dan 10 spesies (Tabel 1). Keseluruhan spesies yang didapatkan tersebut yakni Pelargoderus bipunctatus, Pterolophia uniformis, Pterolophia melanura, Pterolophia sp., Ropica honesta, Ropica marmorata, Ropica javana, Sybra alternans, Sybra binotata, dan Coptops sp. 
Tebel 1. Spesies kumbang antena panjang yang ditemukan di kebun tebu (KT), kebun jati (KJ) dan kebun campuran (KC).

\begin{tabular}{lrrrr}
\hline Subfamili / Tribe / Spesies & KT & KJ & KC & Jumlah \\
\hline Lamiinae & & & & \\
$\begin{array}{l}\text { Monochamini } \\
\text { Pelargoderus bipunctatus }\end{array}$ & 0 & 0 & 2 & 2 \\
Pteropliini & & & & \\
$\begin{array}{l}\text { Pterolophia uniformis } \\
\text { Pterolophia melanura }\end{array}$ & 10 & 5 & 16 & 31 \\
Pterolophia sp. & 17 & 40 & 39 & 96 \\
Apomecynini & 1 & 0 & 0 & 1 \\
Ropica honesta & 19 & 21 & 24 & 64 \\
Ropica marmorata & 11 & 14 & 19 & 44 \\
Ropica javana & 1 & 1 & 2 & 4 \\
Sybra alternans & 33 & 84 & 46 & 163 \\
Sybra binotata & 0 & 0 & 3 & 3 \\
Mesosini & & & & \\
Coptops sp. & 0 & 0 & 1 & 1 \\
\hline Jumlah individu & 92 & 165 & 152 & 409 \\
\hline Jumlah spesies & 7 & 6 & 9 & 13 \\
\hline Indeks keanekaragaman & 1.59 & 1.29 & 1.72 & \\
& & & & \\
\hline
\end{tabular}

Terdapat beberapa spesies unik yang hanya terdapat di satu habitat. Spesies yang hanya ditemukan di kebun campuran yakni $S$. binotata, $P$. bipunctatus dan Coptops $\mathrm{sp}$. sedangkan spesies yang hanya ditemukan di kebun tebu yaitu Pterolophia sp. Pelargoderus bipunctatus berukuran paling besar $( \pm 25 \mathrm{~mm})$ dibandingkan dengan spesies lain, sehingga lebih rentan pada kondisi habitat karena spesies ini membutuhkan tumbuhan yang cocok sebagai inang larvanya. Selain itu, kumbang ini bereproduksi lebih lambat dan membutuhkan sumber daya dan energi yang lebih banyak. Keberadaan spesies unik tersebut pada masing-masing habitat terkait dengan kekhasan dan ketersediaan sumber daya pada habitat tersebut termasuk makanan dan juga tanaman inangnya untuk proses reproduksi. Strategi reproduksi kumbang antena panjang memilih inang yang cocok untuk kehidupan larvanya (Hanks, 1999), dengan menggunakan 2 isyarat penciuman untuk menemukan tanaman inang yang cocok (Linsley, 1959; 31 96 Goldsmith et al., 2007). Sejauh ini, belum ${ }^{1}$ banyak laporan mengenai komunitas ${ }_{44}^{64}$ kumbang antena panjang di perkebunan 44

4 tebu sehingga masih kurang informasi 163

3 tentang tanaman tebu sebagai inang bagi 1 beberapa spesies kumbang antena panjang. ${ }_{13}$ Pramono et al. (2009) melaporkan Dorysthenes sp. merupakan hama pada tanaman tebu, selain itu, Hawkeswood (2011) juga melaporkan bahwa tanaman tebu (Saccharum officinarum L.) merupakan tanaman inang kumbang Pterolophia sp.

Spesies yang paling melimpah atau mendominasi disetiap habitat adalah $S$. alternans (163 individu), kemudian diikuti oleh P. melanura (96 individu). Tingginya kelimpahan spesies tersebut diduga karna sifatnya polifagus ataupun memiliki lebih dari satu tumbuhan inang sehingga ketersediaan sumber daya juga lebih banyak. Jika ditinjau dari kondisi habitat, masing-masing habitat terdapat terdapat semak-semak sebagai sumber makanannya. Kumbang S. alternans sering ditemukan pada semak-semak di daerah dataran rendah, selain juga pada tumbuhan Arachis hypogaea, Ocimum sp. Pandanus sp., Gossypium sp), Artocarpus communis, 
Artocarpus integra, Plumeria sp., Musa paradisiaca serta beberapa tumbuhan genus Euphorbia (Chen et al., 2001). Kumbang $P$. melanura juga memiliki banyak tanaman inang, antara lain Derris robusta, Castilla, Coffea, Hevea, Theobroma, Actinophora, Artocarpus integra, Butea monosperma, Cassia auriculata, Derris eliptica, Erythrina lithosperma, Ficus rempelas, Piper, Tectona, Canarium, Ceiba, Citrus, Deguelia, Gravillea robusta, Magnifera indica, Acacia mangium, Artocarpus anisophyllus, Diptorocarpus tempehes, Endospermum diadenum, Macaranga gigantea, Vernonia arborea dan Pinus caribaea (Makihara et al., 2002).

Berdasarkan hasil analisis nilai indeks keanekaragaman (Tabel 1), keanekaragaman jenis berada dalam kategori sedang, artinya keberadaan kumbang antena panjang masih didukung oleh ketersediaan sumber daya pada masing-masing habitat. Keanekaragaman tertinggi pada habitat kebun campuran $(\mathrm{H}=$ 1,846) kemudian diikuti pada kebun tebu $(\mathrm{H}=1,723)$ dan paling rendah pada kebun jati $(\mathrm{H}=1,51)$. Tingginya keanekaragaman pada kebun campuran dibandingkan habitat yang lain karena kondisi habitat yang berbeda dimana kebun campuran merupakan habitat yang memiliki komposisi tumbuhan yang berbeda-beda (polikultur) dibandingkan dengan dua habitat lain yang cenderung monokultur, sehingga memungkinkan kehadiran kumbang antena panjang. Keberadaan kumbang antena panjang pada suatu habitat sangat dipengaruhi oleh jenis-jenis pohon atau tumbuhan (Ohsawa, 2004; 2010), selain itu kelimpahan kumbang antena panjang juga dipengaruhi oleh pohonpohon dari jenis dan usia yang sama (Alekseev, 2007). Meng et al. (2013) melaporkan adanya hubungan positif antara jumlah spesies kumbang antena panjang dengan jumlah jenis tumbuhan dalam suatu habitat, dimana keragaman jenis tumbuhan secara tidak langsung mencerminkan ketersediaan berbagai jenis kayu yang mati.

Kesamaan komunitas kumbang antena panjang berdasarkan indeks kesamaan Bray-Curtis, tertinggi $(0,795)$ antara habitat kebun campuran - kebun jati. (Tabel 2). Berdasarkan dendogram yang dibentuk, terdapat dua kelompok komunitas kumbang yaitu kebun jati - kebun campuran dan kebun tebu (Gambar 1). Terdapat kemiripan komunitas kumbang antena panjang antara kebun jati - kebun campuran $(79,5 \%)$. Kemiripan komposisi kumbang antena panjang antar kedua habitat tersebut diduga karena adanya kemiripan kondisi habitat. 

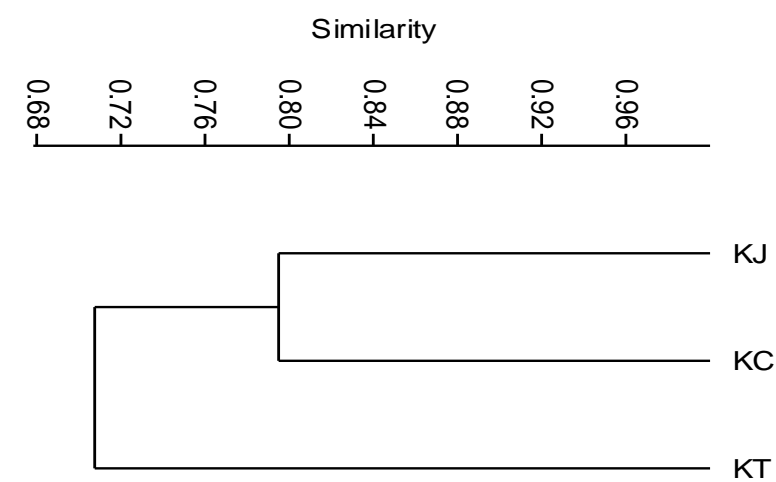

Gambar 1. Dendogram kesamaan komunitas kumbang antena panjang pada berbagai tipe habitat menggunakan metode pair group average.

Table 2. Matriks kesamaan komunitas kumbang antena panjang pada kebun tebu (KT), kebun jati (KJ) dan kebun campuran (KC) berdasarkan metode Bray-Curtis distance.

\begin{tabular}{llll}
\hline \multirow{2}{*}{ Habitat } & \multicolumn{3}{l}{ Matriks kesamaan komunitas } \\
\cline { 2 - 4 } & KT & KJ & KC \\
\hline KT & 1 & 0.669 & 0.746 \\
KJ & 0.669 & 1 & 0.795 \\
KC & 0.746 & 0.795 & 1 \\
\hline
\end{tabular}

Berdasarkan kurva akumulasi spesies berupa nilai estimasi $S$ observasi (10 spesies) dan estimasi Jacknife-2, jumlah spesies yang dikumpulkan dari semua habitat mencapai $76,5 \%$ dari keseluruhan spesies yang ada (13,08 spesies) (Gambar 2).

Jumlah spesies yang dikumpulkan berdasarkan $S$ observation masih kurang dibandingkan dengan estimasi Jacknife-2. Kurva akumulasi jumlah keseluruhan spesies yang dikumpulkan dari tiga habitat menunjukkan tidak tercapainya asimtot sampling yang berarti bahwa daftar spesies kumbang yang terdapat di kebun tebu, kebun jati dan kebun campuran belum lengkap. Sataral (2015) melaporkan bahwa belum optimal jumlah spesies kumbang antena panjang yang dikumpulkan pada lima tipe habitat di hutan pendidikan gunung walat karena jumlah koleksi dan jenis perangkap yang digunakan untuk koleksi kumbang antena panjang belum maksimal.

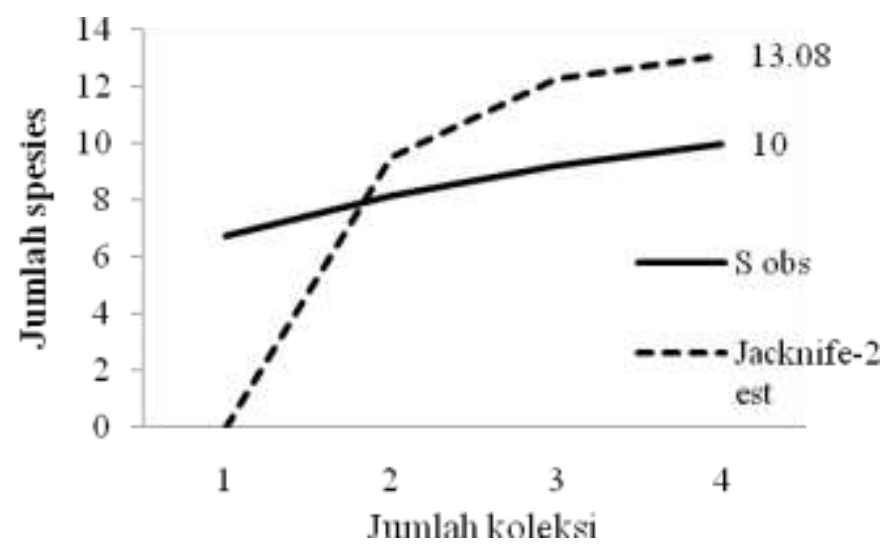

Gambar 2. Kurva akumulasi spesies kumbang antena panjang pada keseluruhan habitat setiap koleksi berdasarkan data observasi dan estimasi Jacknife-2

\section{UCAPAN TERIMAKASIH}

Terimakasih kepada saudari Endang Prasetyawati Wahyuningsih S.Si yang telah membantu mengoleksi sampel di lapangan. Ucapan terimakasih pula kepada para peneliti dan staf di Laboratorium Entomologi, Divisi Zoologi, Pusat Penelitian Biologi LIPI-Cibinong yang 
telah membantu proses preservasi dan identifikasi spesimen.

\section{DAFTAR PUSTAKA}

Alekseev, V.I., 2007, Longhorn beetles (Coleoptera: Cerambycidae) of Kaliningrad Region, Acta Biol, Vol 7(1): 37-62.

Bezark, L.G., 2014, A Photographic catalog of the cerambycidae of the New World, Version 7 April 2014. [Internet].

Tersedia pada:https://apps2.cdfa.ca.gov/public Apps/plant/bycidDB/wdefault.asp?w $\underline{\underline{E} \text {. }}$.

Chen, H., Ota, A., Fonash, G.E., 2001, Infestation of Sybra alternans (Cerambycidae: Coleoptera) in a Hawaii banana plantation, Proc Hawaiian Entomol Soc, Vol 35:119122.

Cherepanov, A.I., 1990, Cerambycidae of Northern Asia Volume 3 Lamiinae. Zolotarenko GS, editor, New Delhi (IN) : Oxonian Press.

Dagobert, K.K., Klimaszewski, J., Mamadou, D., Daouda, A., Mamadou, D., 2008, Comparing beetle abundance and diversity values along a land use gradient in tropical Africa (Oumé, Ivory Coast), J Zool Stud, Vol 47(4): 429-437.

Goldsmith, S., 2007, Density of longhorned beetles (Coleoptera: Cerambycidae) differs at different elevations in Hawaiian montane forest, $\mathrm{J}$ Southwestern Nat, Vol 52(3):364-370

Goldsmith, S., Gillespie, H., Weatherby, C., 2007, Restoration of Hawaiian montane wet forest: endemic longhorned beetles (Cerambycidae:
Plagithmysus) in Koa (Fabaceae: Acacia koa) plantations and in intact forest, Southwestern Nat, Vol 52(3):356-363.

Hanks, L.M., 1999, Influence of the larval host plant on reproductive strategies of cerambycid beetles. Annu Rev Entomol, Vol 44:483-505.

Hawkeswood, T.J., 2011, Review of the biology and host plants of several species of Pterolophia Newman, 1842 (Coleoptera: Cerambycidae) from Papua New Guinea and the Solomon Islands, J Calodema, Vol 164:1-4

Heffern, D.J., 2013, A Catalog and bibliography of longhorned beetles from Borneo (Coleoptera : Cerambycidae, Disteniidae and Vesperidae ), [bibliography]. Elcetronic Version 2013.1.

Herlinda, S., Waluyo, Estuningsih, S,P., Irsan C., 2008, Perbandingan keanekaragaman spesies dan kelimpahan arthropoda predator penghuni tanah di sawah lebak yang diaplikasi dan tanpa aplikasi insektisida, J Entomol Indon, Vol 5(2):96-107.

Hoekstra, J.M., Boucher, T.M., Ricketts, T.H., Roberts, C., 2005, Confronting a biome crisis: global disparities of habitat loss and protection, Ecol Lett. Vol 8:23-29.

Jones, D.T., Susilo, F.X., Bignell, D.E., Hardiwinoto, S., Gillison, A.N., Eggleton, P., 2003, Termite assemblage collapse along a land-use intensification gradient in lowland central Sumatra, Indonesia. Appl Ecol. 40:380-391.

Linsley, E.G., 1959, Ecology of the Cerambycidae. Annu Rev Entomol. 4:99-138. 
Maeto, K., Sato, S., Miyata, H., 2002, Species diversity of longicorn beetles in humid warmtemperate forests: the impact of forest management practices on old-growth forest species in Southwestern Japan, Biodiv Conserv, Vol 11:1919-1937.

Makihara, H., Noerdjito, W.A., Sugiharto, 2002, Longicorn beetles from Gunung Halimun National Park, West Java, Indonesia from 1997 2002 (Coleoptera, Disteniidae and Cerambycidae), Bull of FFPRI, Vol 1(3):189-223.

Makihara, H., Noerdjito, W.A., 2004, Longicorn beetles of Museum Zoologicum Bogoriense, Identified by Dr. E.F. Gilmour, 1963 (Coleoptera: Disteniidae and Cerambycidae), Bull of FFPRI, Vol 3(1):49-98.

Meng, L.Z., Martin, K., Weigel, A., Yang, X.D., 2013, Tree diversity mediates the distribution of longhorn beetles (Coleoptera: Cerambycidae) in a changing tropical landscape (Southern Yunnan, SW China), PLoS ONE, Vol 8(9):1-10.

Sataral, M., 2015, Keanekaragaman dan kelimpahan kumbang antena panjang (Coleoptera:Cerambycidae) di Hutan Pendidikan Gunung Walat, Jawa Barat. Tesis. Institut Pertanian Bogor. Bogor

Sataral, M., Atmowidi, T., Noerdjito, W.A., 2015, Diversity and abundance of longhorn beetles (Coleoptera: Cerambycidae) in Gunung Walat Educational Forest, West Java, Indonesia, Journal of Insect Biodiversity, Vol 3(17): 1-12.

Nieto, A., Alexander, K.N.A., 2010, European Red List of Saproxylic Beetles. Luxembourg (LU: European Union Press.
Noerdjito, W.A., 2008, Struktur komunitas fauna kumbang antena panjang (Coleoptera ; Cerambycidae) di Kawasan Taman Nasional Gunung Ciremai, J Biol Indon, Vol 4(5):371384.

Noerdjito, W.A., 2010, Arti Kebun Raya Bogor bagi kehidupan kumbang antena panjang (Coleoptera, Cerambicidae), J Biol Indon, Vol 6(2): 289-292.

Noerdjito, W.A., 2011, Evaluasi kondisi hutan berdasarkan keragaman kumbang antena panjang Coleoptera : Cerambycidae) di kawasan Gunung Slamet, Berita Biologi, Vol 10(4):521-531.

Ohsawa, M., 2004, Species richness of cerambycidae in larch plantations and natural broad-leaved forests of the central mountainous region of Japan, Forest Ecol Manag, Vol 189: 375-385.

Ohsawa, M., 2010, Beetle families as indicators of coleopteran diversity in forests: a study using malaise traps in the central mountainous region of Japan. Insect Conserv. Vol 14:479484.

Pramono, D., Rival, A., Putranto, D.P., 2009, Dorysthenes sp. (Cerambycidae, Coleoptera), a new potential pest of sugarcane plantation in Indonesia : the biology and its integrated control. Indonesian Sugar Research Institute. [internet]. Pasuruan (ID) : P3GI. Hlm 1-13; [diunduh 2014 Des 28]. Tersedia pada

http://sugarresearch.org/wpcontent/up loads/2009/08/issct-1.pdf

Raje, K.R., Moniem, H.E.M.A., Farlee, L., Ferris, V.R., Holland, J.D., 2012, 
Abundance of pest and benign Cerambycidae both increase with decreasing forest productivity, Agri Forest Entomol. Vol 14:165-169.

Sahabuddin, 2011, Effect of land use change on ecosystem function of dung beetles: experimental evidence from Wallacea Region in Sulawesi, Indonesia, J Biodiv. Vol 12(3):177181.

Susilo, F.X., Indriyati, Hardiwinoto, S., 2010, Diversity and abundance of beetle (Coleoptera) functional groups in a range of land use system in Jambi, Sumatra, J Biodiv, Vol 10(4):195-200. 